group is in place to facilitate that (both our application and the action plan can be found on the school's website). One of the co-chairs of the group has done what is suggested by Professor Kay and taken part in two rounds of application assessment - without doubt, both here in Bristol and nationally, there is evidence that good employment practice is increasing for women who are working in STEM subjects in both higher education and research.

A. Waylen PhD, Athena SWAN Lead, M. Barbour MPhys PhD, Faculty Admissions Officer and Senior Lecturer in Dental Materials Science and Biomaterials, L. McNally BDS MSc FDSRCS Ad Cert Ed PhD, Clinical Dean and Clinical Teaching Fellow in Restorative Dentistry, Bristol DOI: 10.1038/sj.bdj.2013.1001

\section{DOUBTFUL WISDOM}

Sir, the recent Opinion piece by Mansoor et al. on NICE guidelines ${ }^{1}$ raises the issue of wisdom teeth and whether to remove them. As referred to in their article, we followed patients with asymptomatic lower third molars for a year ${ }^{2}$ and observed the development of symptoms and the number of teeth extracted. Indeed over 5\% of all teeth studied were removed after one year; however, a small number of these had no recorded justification for removal.

Whilst the research base for what happens if third molars are left may not be strong, we do know that taking out asymptomatic wisdom teeth is often associated with some fairly unpleasant side effects. In addition to those mentioned, we should not forget quality of life issues. We previously found that time off work, ability to chew food, ability to swallow, and loss of self-esteem were also of concern to the patient. ${ }^{3}$ When we sought to identify the most significant factor (by asking all OMFS consultants in Scotland, all dentists in Tayside and retrospectively asking 120 patients to rank the side effects they experienced after third molar removal), clinicians ranked pain as the most significant complication, whilst patients identified interference with eating. ${ }^{4}$ Thus a number of additional complications appear to exist which may impact upon the patients' well-being.

A randomised controlled trial on this subject would face many challenges not only relating to logistics and ethics but it would have to compensate for differences in access to dental services and in the history of past and current dental disease experienced by the subjects involved in the study.

Further research is clearly still required to improve the evidence base from which to make the conclusion that asymptomatic third molars should be left alone. The wisdom of this is currently in doubt.

\section{Fernandes}

G. R. Ogden

1. Mansoor J, Jowett A, Coulthard P. NICE or not so NICE? Br Dent J 2013; 215: 209-212.

2. Fernandes $M J$ J, Ogden $G R$, Pitts N B, Ogston S A, Ruta D A. Actuarial life-table analysis of lower impacted wisdom teeth in general dental practice. Community Dent Oral Epidemiol 2010; 38: 58-67.

3. Savin J, Ogden G R. Third molar surgery - a preliminary report on aspects affecting quality of life in the early post-operative period. Br J Oral Maxillofac Surg 1997: 35: 246-253.

4. Ogden G R, Bissias E, Ruta D A, Ogston S. Quality of life following third molar removal: a patient versus professional perspective. Br Dent J 1998; 185: 407-411.

DOI: 10.1038/sj.bdj.2013.1002

\section{HPV CONCERN}

Sir, I am concerned about a new group of patients I have been seeing in my practice recently. There is a growing number of patients who have developed oral cancer in innocuous-looking lesions in the oral cavity. There is no tobacco/betelnut/paan habit or traumatic, sharp teeth present, and these are young patients, between 20 and 30 years of age.

One such patient was only 19 -yearsold when she came to me with a tongue ulcer. The chief complaint of the patient was about a small painless ulcer on the side of the tongue which had not prompted her to seek treatment initially. The ulcer did not heal and did not respond to treatment with mouthwashes, glycerine application, or any of the conservative modes of treatment.

The general practitioner kept treating her for more than two months but did not take it seriously and kept treating it, without referral to an oral medicine or oral pathology specialist. It was only when more symptoms developed, and the ulcer increased in size, that there was serious concern. Unfortunately, the general practitioner did not even think of cancer, as there were no related habits, and/or sharp traumatic margins of the teeth, so that by the time the referral was made the cancer had become well-developed and involved deeper areas.

When I examined the patient the cervical lymph nodes were also involved and I gave the diagnosis of squamous cell carcinoma immediately, taking a biopsy of the ulcer and sending it for histological examination. The report was 'squamous cell carcinoma, keratinising, moderately-differentiated' and 'surgical margins of resection involved by tumour'.

Surgery had to be extensive, with cervical node dissection, and it was very disfiguring.

Needless to say, the patient was mentally traumatised and went into depression. Unfortunately, the patient has stopped coming for follow-up. When I discussed the aetiology with the surgeon and other pathologists, human papilloma virus was the commonest answer. There has been a marked rise in such cases across the globe and sexual habits and practices seem to be the major cause. It is estimated that the frequency of oral cancer due to HPV is greater than for other causes such as tobacco usage.

A. M. Havewala By email DOI: 10.1038/sj.bdj.2013.1003 